\title{
Variabilidade das correntes na plataforma interna ao largo de Tramandaí, RS durante o verão de 2014
}

\author{
Mauro M. ANDRADE, Elírio E. TOLDO Jr. \& José C. NUNES
}

Centro de Estudos de Geologia Costeira e Oceânica, Universidade Federal do Rio Grande do Sul. Av. Bento Gonçalves, 9500, CEP 91.540-000, Porto Alegre, RS, Brasil. E-mail: mauromichelena@gmail.com, toldo@ufrgs.br, jose.nunes@ufrgs.br.

Recebido em 03/2015. Aceito para publicação em 07/2016.

Versão online publicada em 26/08/2016 (www.pesquisasemgeociencias.ufrgs.br)

\begin{abstract}
Resumo - Os fenômenos da ressurgência e subsidência costeira em regiões com pequenas profundidades ainda são pouco compreendidos no litoral brasileiro. 0 presente trabalho visa obter um melhor entendimento das condições oceanográficas em águas rasas, tais como as forçantes das correntes costeiras e das oscilações do nível do mar. Um perfilador acústico de ondas e correntes, AWAC, da marca Nortek, foi fundeado a $11 \mathrm{~m}$ de profundidade ao largo da praia de Tramandaí, programado para registrar uma série contínua de dados de ondas e correntes, com início em 17 de dezembro de 2013 e término em 13 de março de 2014 (período do verão). Os resultados indicaram que a circulação tem inversões de curto período no sentido das correntes, ora para S, ora para $\mathrm{N}$. Também foi possível verificar velocidades máximas de 0,6 e 0,9 m. $\mathrm{s}^{-1}$ no fundo e em superfície, respectivamente. Ademais, um fluxo resultante para S, de aproximadamente $0,018 \mathrm{~m} . \mathrm{s}^{-1}$ foi calculado com base no perfil médio da coluna de água. Além disso, foram encontrados indicativos de ressurgência e subsidência costeira, através das análises da direção do vento e das correntes, das variações na temperatura da água e também do nível médio do mar.
\end{abstract}

Palavras-chave: Correntes costeiras, ressurgência costeira, subsidência costeira, perfilador acústico de ondas e correntes.

\begin{abstract}
VARIABILITY OF CURRENTS ON THE INNER SHELF OF TRAMANDAÍ, RS DURING THE SUMMER of 2014. Upwelling and Downwelling events in very shallow water still are poorly understood on brazilian coastal. This work aims to obtain a better understanding of ocean circulation in shallow waters, such as coastal currents and sea level oscillations. An acoustic waves and currents profiler, AWAC, Nortek brand, was anchored at $11 \mathrm{~m}$ depth off Tramandaí beach, which was programmed to record a continuous series of waves and currents data, beginning on December 17, 2013 and ending on March 13, 2014 (summer). The results indicated that in the inner shelf the direction of the currents for short periods reverses, sometimes Southward, sometimes Northward. Also, it was observed the maximum velocities of 0.6 and $0.9 \mathrm{~m} . \mathrm{s}^{-1}$ on the bottom and on the surface, respectively. In addition, a flow rate of $0.018 \mathrm{~m} \cdot \mathrm{s}^{-1}$ to $\mathrm{S}$ was calculated based on the average profile of the water column. Furthermore, were found indicative of upwelling and downwelling circulation patterns, from wind and current direction analysis as well, variations in water temperature and also in average sea level.
\end{abstract}

Key words: Coastal currents, upwelling, downwelling, acoustic wave and current profiler.

\section{Introdução}

Em todo o planeta grandes centros urbanos se desenvolveram nas proximidades das zonas costeiras, principalmente devido à possibilidade de instalação de portos, a abundante fonte de recursos naturais, como por exemplo, o pescado, e também às atividades ligadas ao lazer. No Brasil, $23 \%$ da população residem em zonas costeiras, sendo que a densidade demográfica desta região é 5 vezes maior do que a média nacional (Nakano, 2006).
Neste contexto, o estudo da porção mais próxima à costa da plataforma continental torna-se muito importante, uma vez que aspectos relacionados à segurança da navegação, à dinâmica dos sedimentos, à disponibilidade de nutrientes, à vida dos organismos planctônicos na zona eufótica e à contaminação das águas marinhas pelos poluentes devem ser conhecidos. Além disso, problemas relacionados diretamente às forçantes hidrodinâmicas, reforçam a necessidade do conhecimento não somente dos efeitos, mas também das causas e da variabilidade espaço-temporal das correntes cos- 
teiras.

Ao longo de toda a costa brasileira bem como no litoral do Rio Grande do Sul (RS), há um déficit de séries temporais longas de dados observacionais de ondas, correntes e nível do mar, e também há falhas na distribuição geográfica deste tipo de amostragem (Costa e Möller, 2011). Tanto quanto, a variabilidade das correntes costeiras nas escalas temporais interanuais, sazonais, sinóticas e diurnas como, as principais forçantes causadoras desses movimentos, ainda não são bem compreendidas (Zavialov et al., 2002).

0 primeiro estudo sobre correntes costeiras remonta à década de 1970, e foi descrito em Figueiredo Jr. (1980). Este trabalho pioneiro consistiu em dois fundeios de curta duração, de 36 horas cada, onde foi observada a influência da passagem de um sistema atmosférico na hidrodinâmica local. Pode-se citar ainda os trabalhos mais recentes de Zavialov et al. (2002), Strauch et al. (2009) e Costa \& Möller (2011), os quais apresentaram análises de dados resultantes de campanhas oceanográficas ao longo do litoral. Os trabalhos mencionados reportaram uma circulação em águas rasas dirigidas pelo vento, observando a passagem de sistemas meteorológicos. Também foram verificados fluxos de baixas frequências predominantemente barotrópicos, com correntes residuais para Nordeste ou Sudoeste, dependendo da estação do ano.

Outro comportamento oceanográfico identificado na costa do RS, mas ainda pouco compreendido, é a chamada ressurgência e subsidência costeira. Esse fenômeno foi sugerido primeiramente no trabalho de Calliari \& Fachin (1993), através de observações realizadas em um curto fundeio. Recentemente, este fenômeno também foi identificado em fundeios de ADCP e descrito brevemente em Costa (2009).

No que diz respeito à variabilidade do regime de vento, dominam ao longo do ano ventos do quadrante NE. Contudo, inversões periódicas na direção, para SO, são observadas durante a passagem de frentes meteorológicas, as quais são mais frequentes no outono e inverno. 0 campo de ventos também apresenta grande variabilidade interanual ligadas a eventos El Niño Oscilação Sul. Durante anos de El Niño, ventos de NE predominam, enquanto que em anos La Niña, a frequência de ventos SO é maior do que a observada regularmente (Barros et al., 2002; Piola et al., 2005).

A maré astronômica é mista com predominância semi-diurna, com amplitude média de 0,3 m (Almeida et al., 1997), a qual é classificada como um regime de micromaré e por esse motivo considerada pouco importante na circulação. Essa pequena amplitude de maré ocorre por causa da proximidade com um ponto anfidrômico no Atlântico Sul e também pela configuração retilínea da linha de costa, sem irregularidades que poderiam amplificar, por efeitos de ressonância ou convergência, as amplitudes das marés (Villwock \& Tomazelli, 1995).

No entanto, as forçantes meteorológicas podem fazer com que o nível se eleve em até $1 \mathrm{~m}$ acima daqueles previstos para a maré astronômica (Almeida et al., 1997). Em uma região mais ao sul do RS, Praia do Cassino, sobre elevações de 1,9 $\mathrm{m}$ relacionadas à forçantes meteorológicas foram medidas (Parise et al., 2009). Durante eventos de passagens de frentes frias, mais comuns durante os meses de inverno, os ventos fortes de SO, com velocidades médias de $8 \mathrm{~m} . \mathrm{s}^{-1}$, resultam em níveis mais altos do mar. Deste modo, as grandes variações no nível do mar ocorrem devido à fatores meteorológicos como o vento e as variações na pressão atmosférica, e são os causadores das marés meteorológicas muito relevantes para o litoral do RS (Siegle \& Calliari, 2008).

Apesar dos trabalhos publicados, citados acima, abordarem as questões da circulação por correntes na costa do RS, os fenômenos da ressurgência e subsidência costeira em regiões com pequenas profundidades (águas muito rasas) ainda são pouco compreendidos. Ademais, a costa do RS é um local chave para o entendimento das correntes costeiras induzidas pelo vento.

A fim de monitorar as condições oceanográficas, incluindo a medição das direções e velocidades das correntes, foi fundeado um perfilador acústico de ondas e correntes (AWAC/Nortek) à 11 m de profundidade na Praia de Tramandaí, RS. Os resultados encontrados mostram uma grande variabilidade na direção e na intensidade das correntes associada à forçante meteorológica. Também foram encontrados claros indicativos de ocorrência do transporte de Ekman em uma área de águas muito rasas.

\section{2 Área, materiais e métodos}

\section{1 Área de estudo}

A Plataforma Continental do RS localizada entre os paralelos $29^{\circ} \mathrm{S}$ e $34^{\circ} \mathrm{S}$, se estende desde a margem continental até a isóbata de $180 \mathrm{~m}$ e possui na parte norte uma largura em torno de 110 $\mathrm{km}$ e ao sul, $170 \mathrm{~km}$ (Calliari et al., 2009). A declividade do fundo, entre $0,03^{\circ}$ e $0,08^{\circ}$, é considerada suave (Toldo Jr. et al., 2006). Com orientação NE-SO, a extensa linha de costa do Estado, com apro- 
ximadamente 620 km é retilínea, sem reentrâncias e caracteriza-se por uma faixa contínua de praias oceânicas arenosas com largura variando entre 50 e 100 metros e declividade entre 3 e 5 graus (Fachin, 1998).

A região em estudo localiza-se na plataforma interna no litoral norte do Estado, ao largo do município de Tramandaí (Fig. 1) e possuí um ângulo regional de $37^{\circ}$ de inclinação em relação ao Norte Verdadeiro. A praia de Tramandaí apresenta na maioria das vezes duas ou mais linhas de arrebentação, os bancos arenosos apresentam-se dispostos longitudinalmente à linha de praia (Ma, 2013). A praia de Imbé, vizinha à Tramandaí e localizada ao norte do canal da Lagoa de Tramandaí, foi caracterizada no trabalho de Toldo et al. (1993) através de aspectos morfodinâmicos como intermediária a dissipativa.

\subsection{Materiais e métodos}

Um perfilador acústico de ondas e correntes, modelo AWAC, da marca Nortek, com frequência de $1 \mathrm{MHz}$, foi fundeado a $2 \mathrm{~km}$ da costa e a $11 \mathrm{~m}$ de profundidade. Durante o período em que este equipamento esteve em funcionamento, de $17 \mathrm{de}$ dezembro de 2013 a 13 de março de 2014, foram registrados dados de velocidade e direção de correntes do fundo a superfície, divididos em células de $0,5 \mathrm{~m}$ de espessura (total de 30 células), realizando uma média amostral de $60 \mathrm{~s}$ a cada $600 \mathrm{~s}$. Cabe ressaltar que foi utilizada uma distância em branco (em inglês, blanking distance) de 0,4 m, e que as células que se encontravam fora da coluna d'água foram removidas através do programa Storm da fabricante Nortek. O AWAC também amostrou dados de nível do mar (pressão) e de

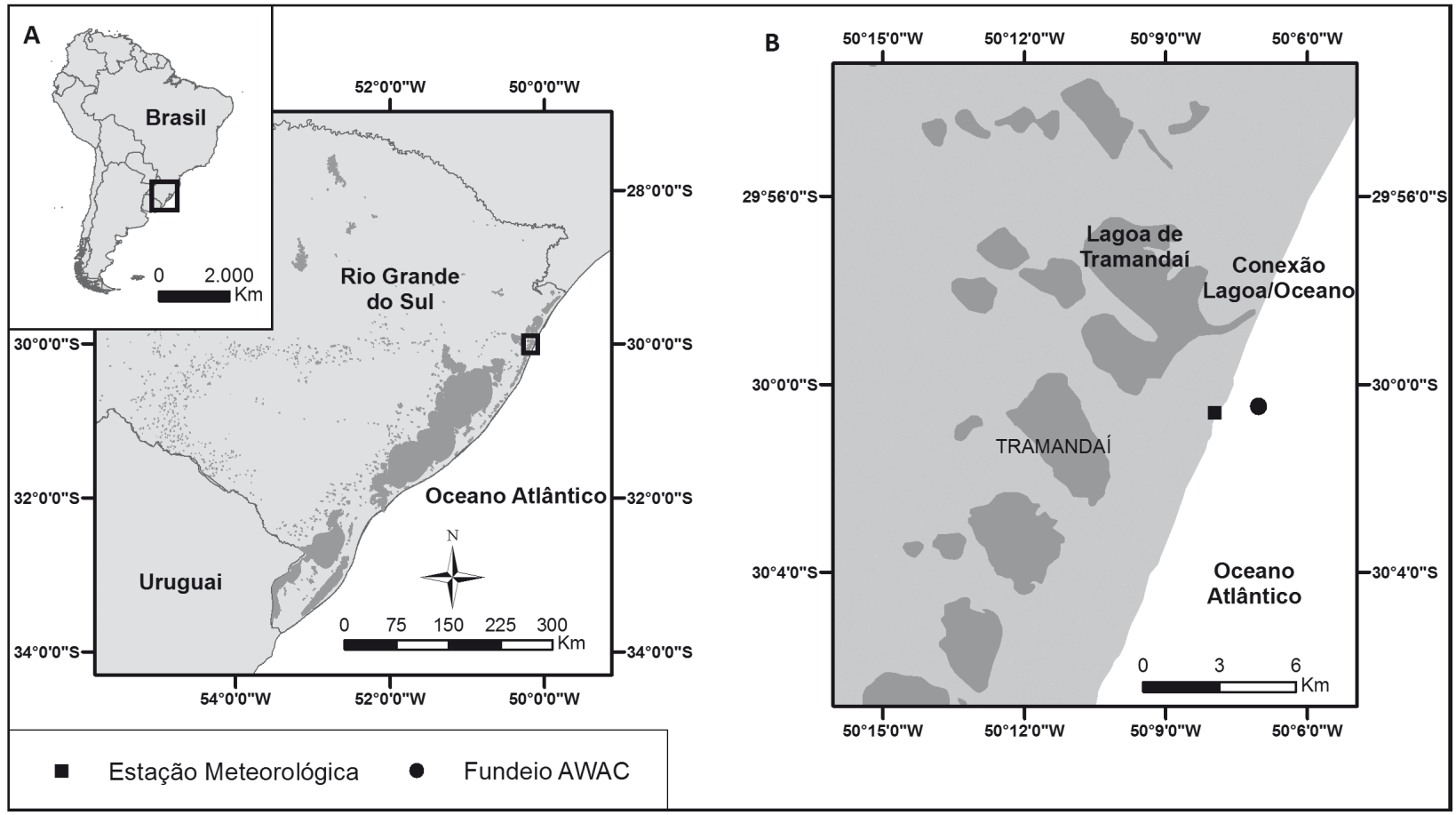

Figura 1. Área de estudo. A) Localização aproximada com destaque para o estado do Rio Grande do Sul; B) Plataforma Interna ao largo de Tramandaí. Círculo e quadrado pretos indicam o local do fundeio do AWAC e da Estação Meteorológica, respectivamente.

temperatura da água. Além destes, o equipamento registrou dados com os parâmetros das ondas, aqui não considerados visto este trabalho ter como objetivo apenas o estudo do padrão de correntes dessa região.

Uma estação meteorológica automática da marca Vaisala, modelo MAWS 301, instalada e mantida pelo Instituto Nacional de Meteorologia (INMET), forneceu os dados de direção e intensidade do vento, utilizados neste trabalho. Esta estação está localizada a pouco mais de $2 \mathrm{~km}$ do local de fundeio, em uma área livre de obstáculos com sensores posicionados a $10 \mathrm{~m}$ de altitude em relação ao terreno. Os dados de vento foram amostrados a cada minuto e integralizados para um período horário.

A fim de orientar o sistema de referência dos dados em relação ao alinhamento da costa, os dados de vento e de velocidades de correntes foram rotacionados em $20^{\circ}$ em relação ao Norte Verdadeiro, seguindo a orientação da isóbata de $11 \mathrm{~m}$. Estes também foram decompostos em componentes longitudinal e transversal à costa, seguindo a metodologia descrita em Miranda et al. (2002). 
Com o objetivo de remover as oscilações de alta frequência, utilizou-se um filtro de passa baixas do tipo Lanczos-Cosseno (Thompson, 1983), que remove $95 \%$ das oscilações com frequências menores que $1 / 40$ h. 0 resultado são as chamadas oscilações de baixas frequências.

As análises espectrais realizadas seguiram o método proposto por Welch (1967). No presente trabalho foi aplicada uma janela do tipo Hanning, com sobreposições de $50 \%$, procedimento que resulta em uma estimativa de densidade espectral média, calculada a partir da estimativa de cinco segmentos. Através do uso do janelamento, perde-se resolução espectral; entretanto, aumenta-se a confiabilidade estatística da análise.

Correlações cruzadas foram realizadas para avaliar o quanto uma variável está diretamente relacionada a uma segunda variável. Dessa maneira obtiveram-se os coeficientes de correlação e a diferença de fase em horas para a maior correlação entre as variáveis. 0 coeficiente de correlação negativo representa uma relação inversa e valores positivos uma relação direta, sendo que os valores próximos a 1 e -1 representam a maior correlação. Valores próximos de zero não demonstram uma relação linear.

\section{Resultados e discussão}

Os valores máximos de velocidade de corrente medidos em superfície foram de aproximadamente $0,86 \mathrm{~m} \cdot \mathrm{s}^{-1}$ no eixo longitudinal, e de $0,44 \mathrm{~m} \cdot \mathrm{s}^{-1}$ no eixo transversal à costa. Já na camada próxima ao fundo, foram calculados valores de 0,61 e 0,3 m.s. para as componentes longitudinal e transversal à costa, respectivamente. Costa \& Möller (2011) encontraram valores muito próximos a estes na mesma estação do ano, entretanto em uma região mais ao sul do litoral.

Na figura 2 são apresentadas as séries temporais filtradas do vento (Fig. $2 \mathrm{~A}$ ) e das velocidades de correntes (Fig. 2B e C), próximo à superfície (1 $\mathrm{m})$ e ao fundo $(10 \mathrm{~m})$, para todo o período do fundeio. Inicialmente, pode-se observar em diversos momentos a mudança na direção da corrente causada pelo vento, ou seja, sob o domínio de ventos do quadrante $\mathrm{N}$ a componente longitudinal da corrente esteve orientada para $\mathrm{S}$, e com vento de $\mathrm{S}$ a corrente fluiu para N. Ademais, pode-se observar que a magnitude da velocidade do vento é uma ordem de grandeza maior que dá corrente longitudinal. Fluxos em direção à costa ou para o mar aberto também foram observados na componente transversal da corrente (Fig. 2C), inclusive apresentando cisalhamento da corrente na coluna de água, ou seja, um fluxo na camada de fundo em direção à costa e um fluxo de retorno na superfície em direção ao oceano. 0 inverso desse padrão de movimento, ou seja, um fluxo na superfície em direção à costa e no sentido contrário no fundo, também foi observado em diversos momentos.

Na figura 3 se observa o perfil vertical médio das velocidades da corrente para todo o período do fundeio. Nota-se um fluxo bidirecional na componente longitudinal (em preto), para $S$ na metade superior da coluna d'água e para $\mathrm{N}$ na metade inferior. A média das velocidades do perfil para $\mathrm{S}$ é mais intensa. 0 padrão bidirecional (Fig. 3) pode ser interpretado pelo atrito da corrente com o fundo plano e suavemente inclinado para E (1:100), na região do fundeio. Na figura $2 \mathrm{~B}$, se nota que o padrão dos fluxos para $\mathrm{N}$ está em fase, ou seja, tanto as correntes de fundo como as de superfície apresentam o mesmo sentido e magnitude. Entretanto, o comportamento das correntes para S é distinto, com discordâncias na direção e intensidade entre as correntes de superfície e de fundo. No Hemisfério Sul as correntes para S são defletidas para a esquerda, gerando um fluxo em direção ao oceano pela superfície e outro em direção à costa pelo fundo, mas como a profundidade diminui em direção à costa, ocorre o efeito de rampa pelo aumento da resistência ao deslocamento dessa corrente de fundo, diminuindo assim sua intensidade e aumentando o giro em direção à costa, o que resulta em um perfil médio do fundeio com um padrão bidirecional.

A velocidade média do perfil foi de aproximadamente $-0,018 \mathrm{~m} \cdot \mathrm{s}^{-1}$, demonstrando um padrão barotrópico com direção $S$ nesta estação do ano. Costa \& Möller (2011) calcularam uma velocidade média de aproximadamente - 0,06 m.s $\mathrm{s}^{-1}$, também dirigida para sul, para um período entre a primavera e o verão entre os anos de 2006 e 2007 . 0 perfil médio das velocidades na componente transversal à costa (Fig. 3, em cinza) demonstrou um fluxo em direção ao oceano, nas camadas mais superficiais e outro oposto pelo fundo, em direção à costa. 0 fluxo residual integrado desta componente resultou em um valor muito pequeno de $0,002 \mathrm{~m} . \mathrm{s}^{-1}$, em direção ao oceano.

As oscilações do nível do mar e da temperatura da água em baixas frequências podem ser observadas na figura 4. Os registros de nível apresentaram uma variação considerável para o período em estudo, onde se pode verificar, entre o nível mais baixo e o mais alto, uma diferença total de aproximadamente $1,4 \mathrm{~m}$. Foi observado, também, no inicio da série temporal o nível do mar aparentemente mais baixo, e que no final desta série o nível 

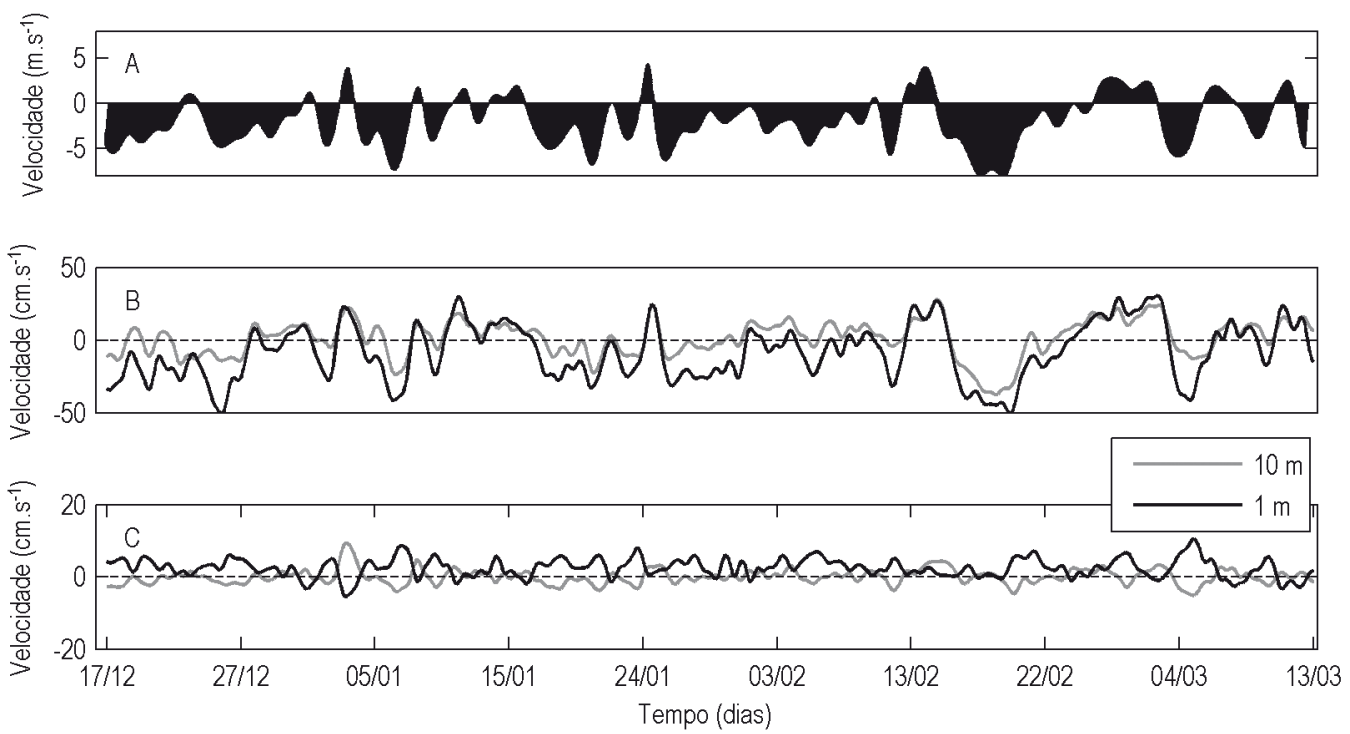

Figura 2. Séries temporais entre 17 de dezembro e 13 de março. A) Dados de vento, valores positivos indicam proveniência do quadrante S, e negativos do quadrante N; B) Componente longitudinal da corrente medidas a $1 \mathrm{~m}$ (preto) e a $10 \mathrm{~m}$ (cinza) de profundidade, os valores positivos indicam fluxos para $\mathrm{N}$ e negativos para $\mathrm{S}$; $\mathrm{C}$ ) Componente transversal da corrente, os valores positivos indicam fluxos em direção ao mar aberto, e negativos em direção à costa.

estava um pouco acima da média, isto pode ser explicado pela predominância de vento de NE no início da série e de vento de SO no final da série. Este mecanismo pode ser interpretado como maré meteorológica negativa e positiva, respectivamente. A série temporal de temperatura da água, a qual foi amostrada no fundo da coluna d'água, demonstra a variabilidade típica da região, com valores próximos a $19^{\circ} \mathrm{C} \operatorname{logo}$ no início do verão, e da ordem de $24^{\circ} \mathrm{C}$ no tempo restante do período de aquisição dos dados.

\subsection{Análises espectrais e correlações}

As análises espectrais realizadas para os dados de corrente longitudinal em superfície e fundo resultaram em maiores energias em torno de 14 dias (Fig. 5A). Observa-se também maior energia ou variância na corrente longitudinal de superfície, quando comparada a de fundo.

As análises da corrente transversal à costa, tanto em superfície quanto no fundo, resultaram em um espectro de energia mais distribuído quando em comparação ao espectro da corrente longitudinal. Entretanto, ainda é verificado um pico de energia em torno de 14 dias e outro, com maior variância próximo de 6 dias (Fig. 5B). Também é possível verificar, na componente transversal da corrente de superfície (Fig. 5B, linha tracejada), um pouco de energia em torno de $24 \mathrm{~h}$, o que pode estar associado à maré astronômica.

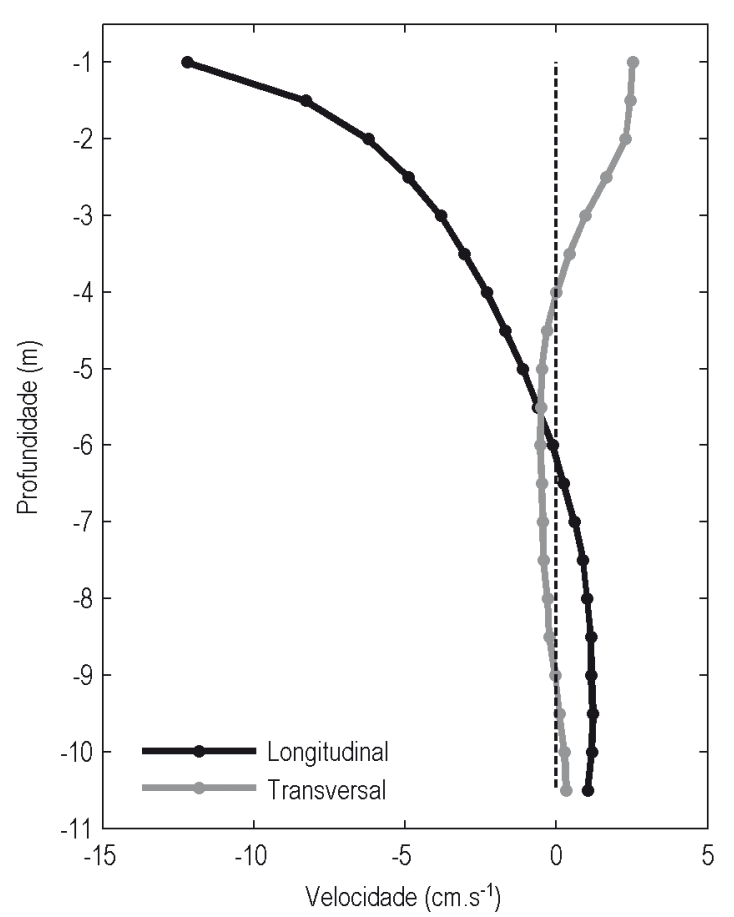

Figura 3. Perfil médio da velocidade da corrente: em preto os valores positivos indicam sentido para $\mathrm{N}$ e negativos para $\mathrm{S}$; em cinza, valores positivos indicam correntes em direção ao oceano e negativos à costa.

Na análise espectral dos dados de vento nota-se maior energia em torno de 21 dias para o vento transversal à costa (Fig. 6). Já para o vento longitudinal é possível observar grande energia em torno de 14 dias. Para as duas componentes do vento também foi verificada grande variância na banda de $24 \mathrm{~h}$. 

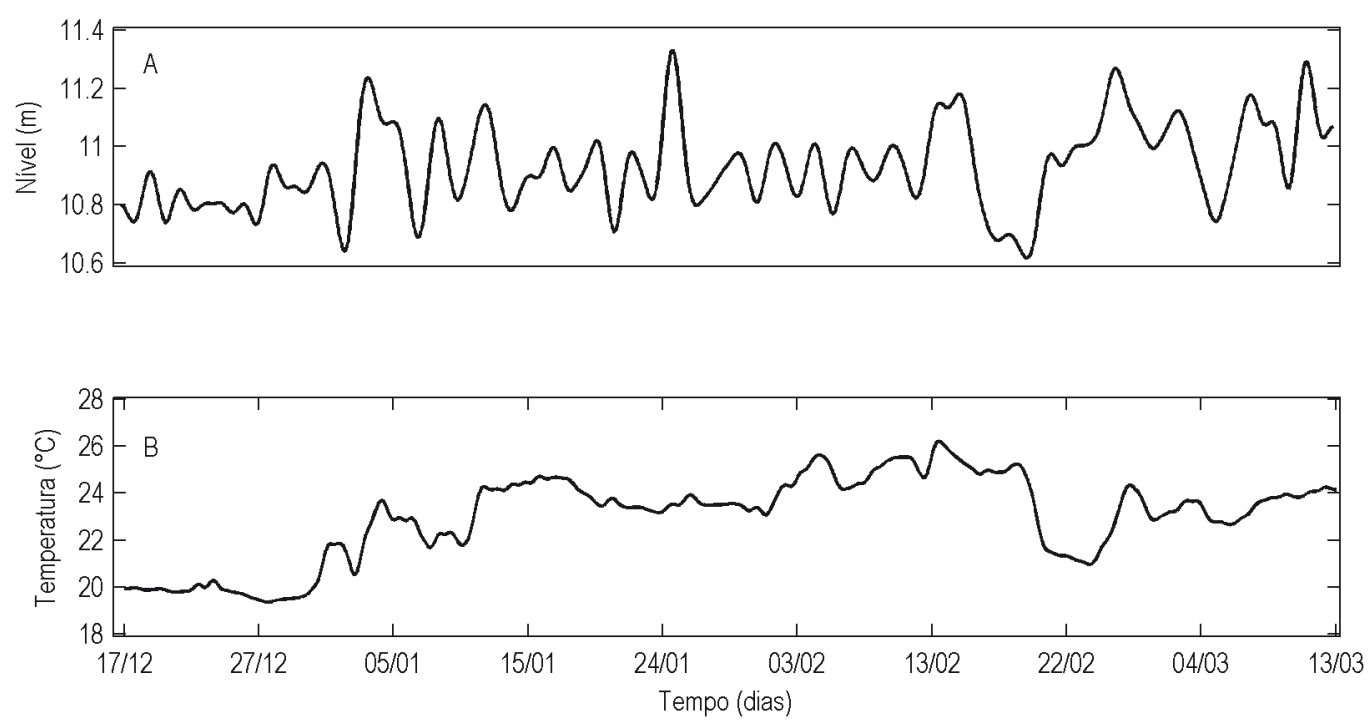

Figura 4. Parâmetros físicos da água adquiridos entre 17 de dezembro e 13 de março. A) Série temporal de nível d’água filtrada; B) Série temporal de temperatura da água.
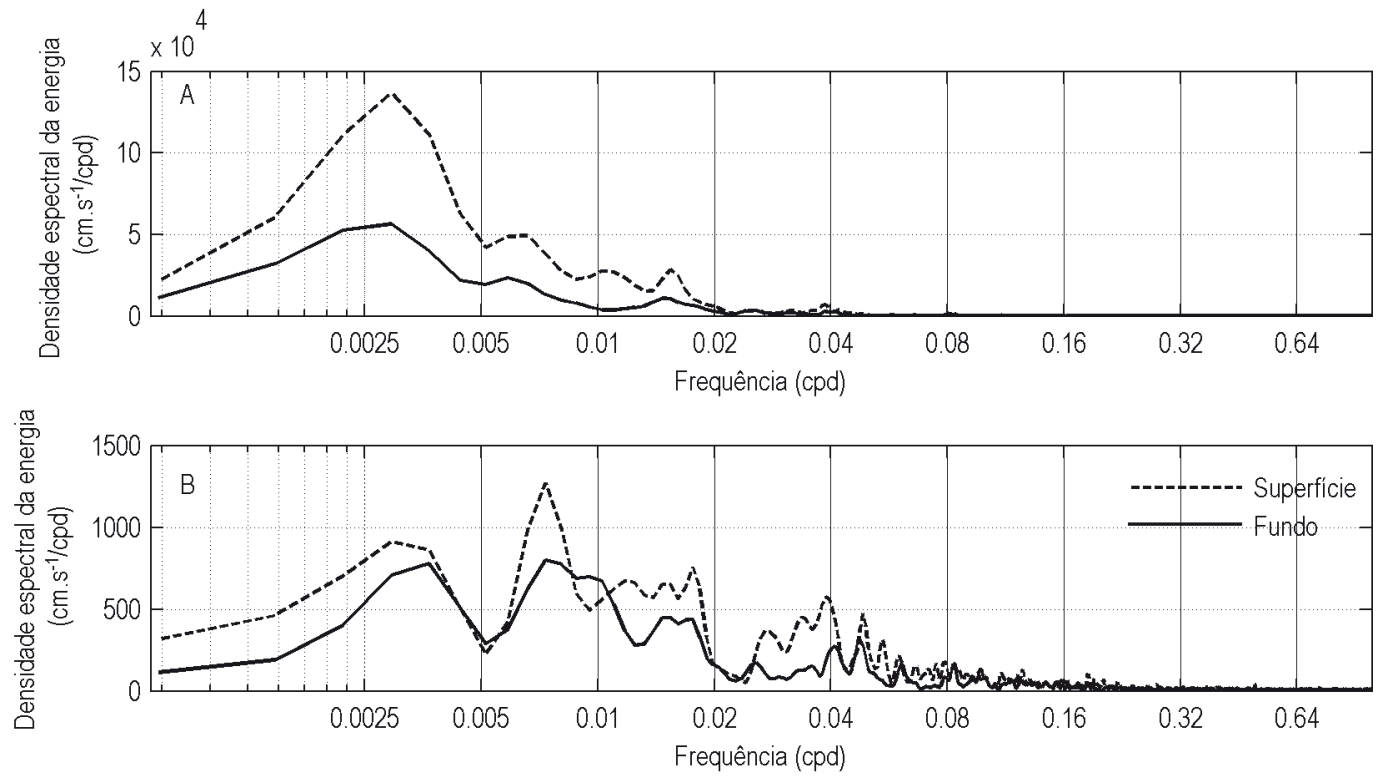

Figura 5. Estimativa de densidade espectral da corrente. A) Componente longitudinal da corrente; B) Componente transversal da corrente.

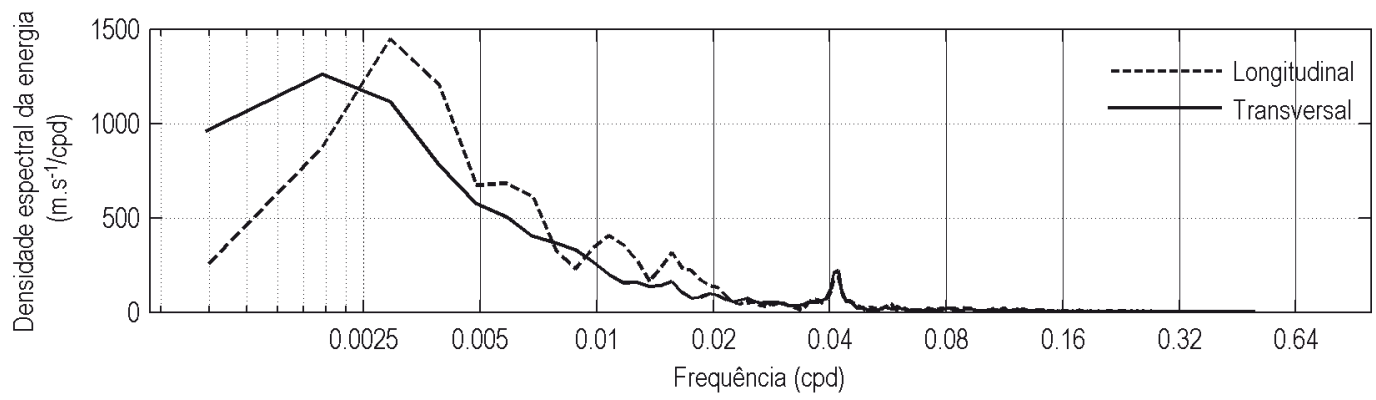

Figura 6. Estimativa de densidade espectral do vento. 
Estes resultados demonstram que a maior variabilidade das séries temporais de velocidade da corrente e da velocidade do vento está associada às baixas frequências, indicando assim o vento como a principal forçante da hidrodinâmica local.

Os resultados das análises de correlação cruzada entre as componentes longitudinais do vento e da corrente (Fig. 7A), filtrados em $40 \mathrm{~h}$, reforçam o encontrado nas análises espectrais, uma vez que foi calculado um coeficiente de correlação máximo na camada de superfície de 0,87 , sem defasagem entre a atuação do vento e uma resposta da corrente. À medida que a profundidade aumenta a defasagem aumenta, sendo que a meia água a defasagem é de $1 \mathrm{~h}$, e em fundo de $2 \mathrm{~h}$. Os valores do coeficiente de correlação entre o vento e as camadas de meio e fundo, resultaram em 0,77 e 0,78, respectivamente.

A correlação entre o vento longitudinal e a corrente transversal (Fig. 7B) apresentou um valor de $-0,54$, com defasagem de $5 \mathrm{~h}$, para a camada de superfície. Para a camada de fundo o coeficiente de correlação foi igual a 0,69 , com $4 \mathrm{~h}$ de defasagem. A correlação negativa encontrada em superfície é explicada pelo transporte de Ekman, para o caso em estudo, valores negativos do vento (vento NE) forçam correntes em direção ao oceano (valores positivos). De maneira oposta, ventos do quadrante $S$ (positivos), forçam um fluxo em direção à costa (valores negativos). Na camada de fundo, a correlação positiva também condiz com o transporte de Ekman, uma vez que, ventos de NE (negativos), promovem correntes em direção à costa (negativos), e ventos de SO (positivos), forçam fluxos em direção ao oceano (positivos).
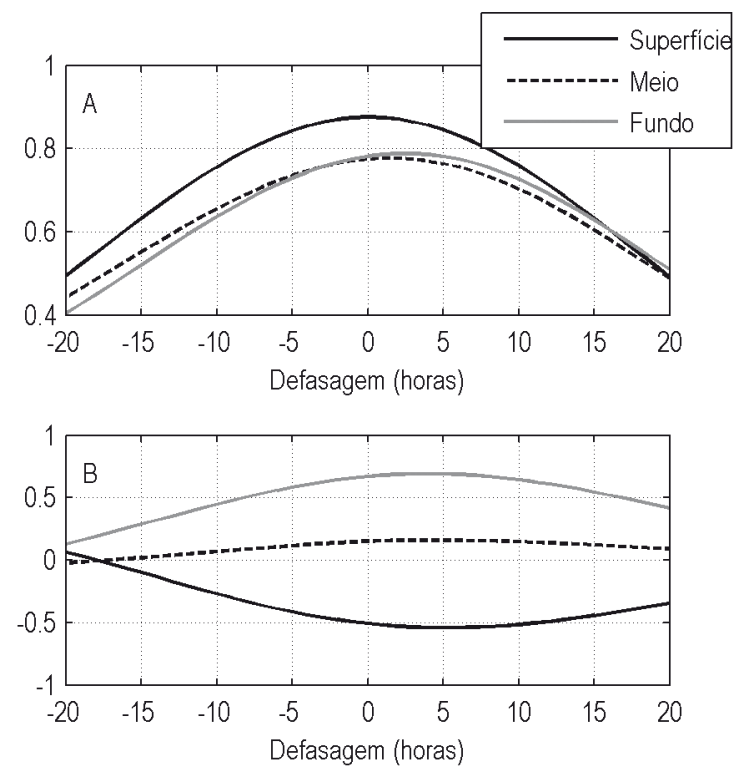

Figura 7. Correlação cruzada entre os dados. A) corrente e vento longitudinais; B) corrente transversal e vento longitudinal.
Estes resultados demonstram que o vento longitudinal se constitui na principal forçante da hidrodinâmica nesta zona de águas rasas, no período do verão. Este padrão também foi encontrado por Costa \& Möller (2011), em uma região mais ao sul do litoral do RS. Entretanto, estes autores encontraram maior defasagem no efeito do vento na corrente, justificando esta defasagem à distância entre o local do fundeio do correntômetro e da estação meteorológica usada para a medição do vento.

Corroborando com os resultados acima apresentados, que demonstraram claramente os efeitos das baixas frequências como forçante principal da circulação nesta região, foi realizada a correlação cruzada entre a série temporal de nível e a componente longitudinal do vento (Fig. 8), a qual resultou em um coeficiente de correlação de 0,74 , com defasagem de $8 \mathrm{~h}$. Já na correlação entre o vento transversal e o nível, obteve-se um coeficiente de correlação igual a 0,47 , com $27 \mathrm{~h}$ de defasagem. As correlações positivas encontradas são explicadas pelo transporte de Ekman, que para a região investigada ocorre da seguinte forma: ventos de $\mathrm{N}$ (negativos) rebaixam o nível na costa, e ventos de $\mathrm{S}$ (positivos) elevam o nível, o que no caso em estudo será chamado, de forma geral, de ressurgência e subsidência, respectivamente.

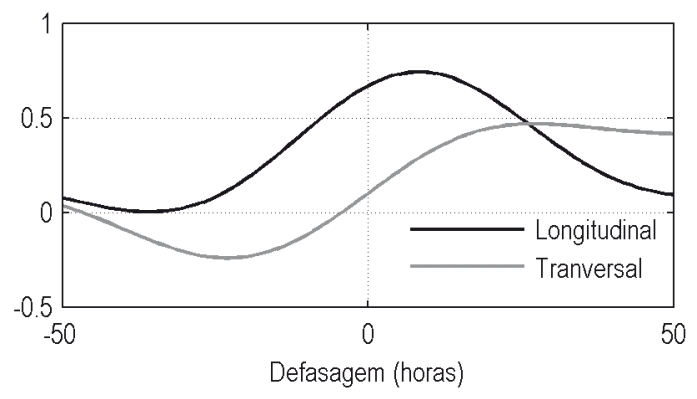

Figura 8. Correlação cruzada entre os dados de nível do mar e as componentes longitudinal (em preto) e transversal (em cinza) do vento.

\subsection{Ressurgência e subsidência costeira}

Analisando os resultados encontrados nas correlações cruzadas e observando de forma integrada as séries temporais, ficam evidentes os padrões de circulação conhecidos como ressurgência e subsidência costeira. Esse mecanismo foi proposto por Ekman (1905), o qual demostra que o vento ao soprar sobre o oceano causa uma corrente superficial inicialmente na mesma direção do vento. Com a deflexão pelo efeito de Coriolis, e ao atingir um estado estacionário de equilíbrio, ocorre o desenvolvimento da chamada espiral de Ekman, com um transporte de massa ortogonal- 
mente à esquerda da tensão do cisalhamento do vento, conhecido como transporte de Ekman. Este transporte se dá em uma camada superficial, cuja espessura é diretamente proporcional à intensidade do vento e à viscosidade turbulenta, denominada de camada de Ekman (Bowden, 1983). Em áreas rasas, como na plataforma continental interna, as escalas horizontais e verticais são muito reduzidas, assim, essa região encontra-se continuamente sob ação de mecanismos inerentes a baixa profundidade, sendo denominada zona de fricção (Stanley \& Swift, 1976). Neste ambiente, as camadas de Ekman de fundo e superfície se sobrepõem, transferindo progressivamente mais tensão de cisalhamento do vento diretamente para o fundo à medida que a profundidade diminui. Esta sobreposição define a região de divergência, ou convergência do transporte de Ekman ortogonal à costa, causadora da subsidência ou ressurgência costeira (Smith, 1981).

Um padrão do modelo de equilíbrio de Ekman foi observado, onde ventos paralelos à costa induzem um transporte ortogonal à linha de costa na camada superficial. No entanto, devido a barreira exercida pela presença da costa, um fluxo de retorno no interior da coluna de água se desenvolve em sentido contrário ao da superfície. No caso da costa oeste do Atlântico, no Hemisfério Sul, ventos do quadrante $\mathrm{N}$ promovem correntes para o $\mathrm{S}$ que causam a já citada ressurgência costeira. De forma contrária, ventos do quadrante S promovem correntes para o $\mathrm{N}$ e com isso, a subsidência costeira. No presente trabalho, há fortes indícios que tanto a ressurgência, como a subsidência costeira, ocorreram em diversos momentos do registro realizado pelo AWAC.

Já haviam sido encontradas evidências do transporte de Ekman na costa do Rio Grande do Sul, entretanto nunca de forma tão clara e em profundidades tão reduzidas como no caso do fundeio em questão, aos $11 \mathrm{~m}$ de profundidade.

A fim de tornar mais compreensível a visualização destes mecanismos, foram selecionados dois períodos. A figura 9 retrata o primeiro período, entre 3 e 4 de janeiro, com duração de mais de 30 $h$, quando ventos de SO estiveram associados com uma corrente longitudinal, totalmente orientada para o N (Fig. 9A). Esse movimento gerou uma corrente de superfície no eixo transversal em direção à costa, e outra de retorno pelo fundo em direção ao mar aberto (Fig. 9B). Além disso, ocorreu um aumento na temperatura d'água de aproximadamente $4^{\circ}$ (Fig. 9C), e também uma elevação do nível do mar em mais de 0,3 m (Fig. 9D), o que claramente caracteriza o já mencionado mecanismo de subsidência costeira.

O segundo período selecionado (Fig. 10), com 40 h de duração, entre os dias 3 e 4 de março, quando foi observado um vento de NE, o qual forçou uma corrente longitudinal orientada para S em toda a coluna d'água (Fig. 10A), que por sua vez, gerou um fluxo transversal na superfície em direção ao oceano, e outro de retorno pelo fundo em direção à costa (Fig. 10B). Com isso, águas com menores temperaturas, cerca de $1^{\circ}$ mais frias, foram advectadas em direção à região mais rasa da
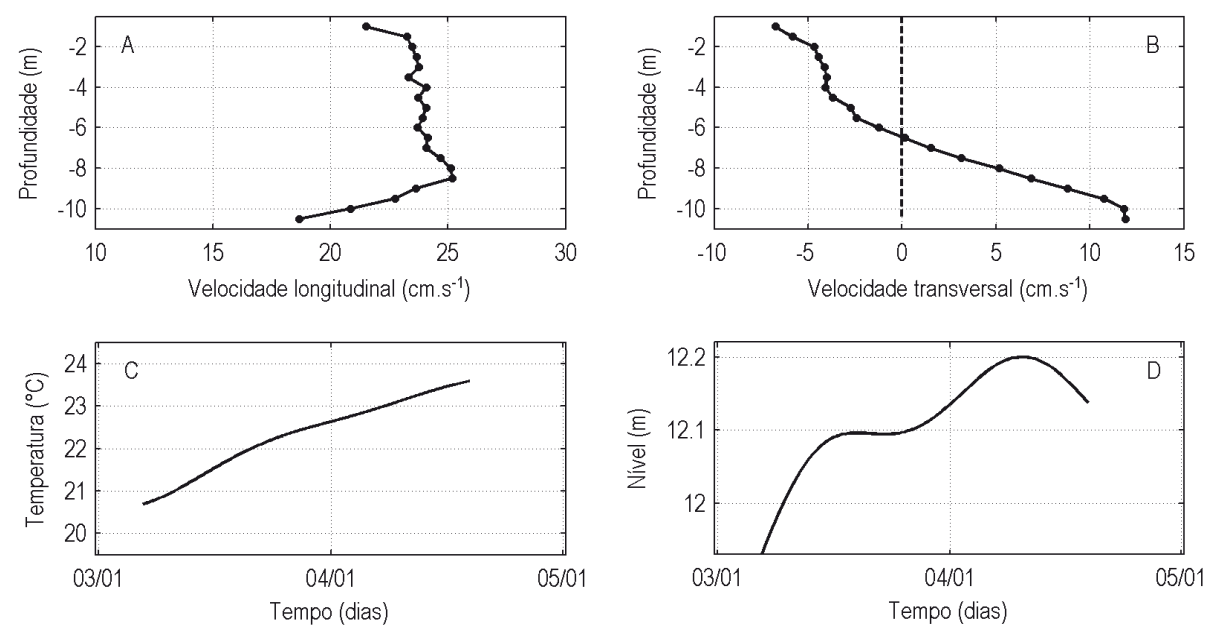

Figura 9. Descrição do mecanismo de subsidência costeira para uma condição de vento SO. A) Perfil médio da velocidade da corrente longitudinal a costa, valores positivos indicam direção N; B) Perfil médio da velocidade transversal à costa, valores positivos indicam fluxo em direção ao oceano, valores negativos indicam direção à costa; C) Temperatura da água no fundo; D) Nível médio do mar. 
plataforma continental (Fig. 10C), e também foi observado um rebaixamento do nível do mar localmente, superior a $20 \mathrm{~cm}$ (Fig. 10D).

As condições meteorológicas e oceanográficas descritas anteriormente possibilitam a interpretação do modelo de circulação teórico proposto inicialmente por Ekman (1905), e posteriormente por Csanady (1976), o qual descreveu a importância do cisalhamento do vento no comportamento das correntes na plataforma continental. Esse último autor propôs que ventos paralelos à costa in- duzem um transporte de Ekman ortogonal à costa na camada superficial e devido a presença da costa, um fluxo de retorno se desenvolve na camada de fundo em sentido contrário ao da superfície.

Esse comportamento tão próximo à zona de surfe, ganha destaque quando é identificado e descrito, devido a sua importância no transporte de sedimentos entre esta região e a porção mais profunda da plataforma continental, na importação e exportação do sedimento de fundo (Pepper \& Stone, 2004).
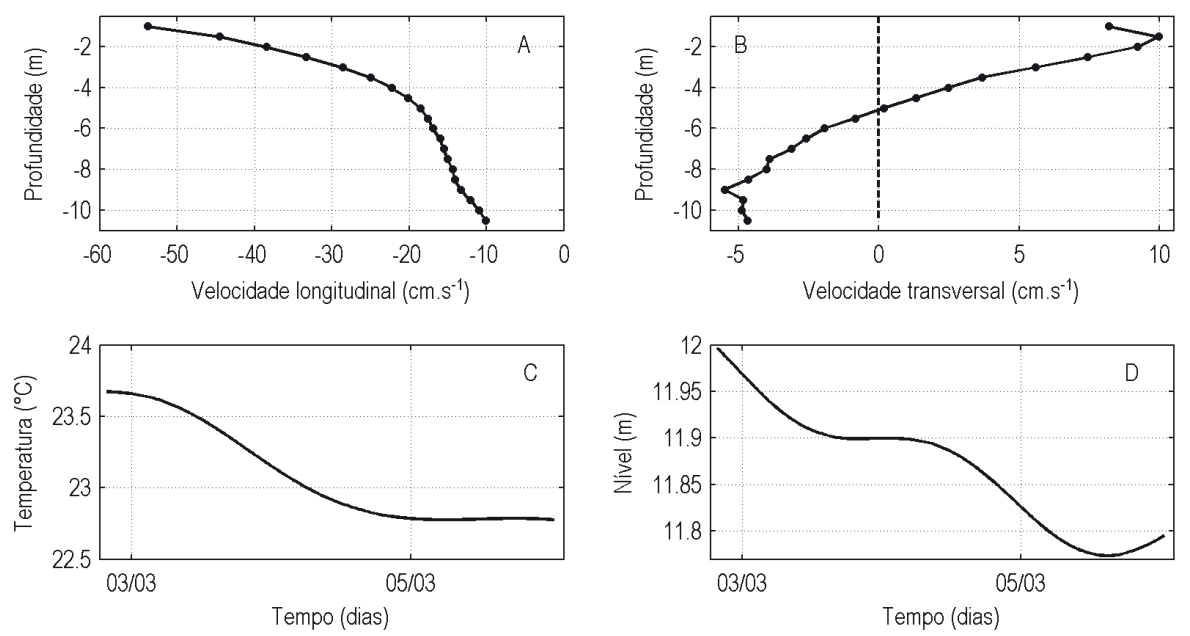

Figura 10. Descrição do mecanismo de ressurgência costeira para uma condição de vento NE. A) Perfil médio da velocidade longitudinal a costa, valores negativos indicam direção S; B) Perfil médio da velocidade transversal à costa, valores positivos indicam fluxo em direção ao oceano, valores negativos indicam direção à costa; C) Temperatura da água no fundo; D) Nível médio do mar.

\section{Conclusões}

Os resultados apresentados demonstram padrões regionais de correntes costeiras que atuam na plataforma interna, no litoral norte do Rio Grande do Sul, e que ainda não tinham sido descritos e interpretados anteriormente. As análises espectrais e as correlações entre a componente longitudinal do vento e das correntes indicaram o domínio desta forçante na hidrodinâmica local.

0 perfil médio de velocidades de todo o registro de correntes indica velocidades mais intensas para S na camada superficial da água em relação à camada de fundo, e a existência de um padrão bidirecional causado pelo atrito do escoamento com o fundo plano e suavemente inclinado para E na região do fundeio.

Os diferentes valores de defasagem entre a atuação do vento e a resposta na corrente em superfície $(0 \mathrm{~h})$ e fundo $(2 \mathrm{~h})$, evidenciam uma rápida resposta da água à ação do vento. Além disso, foi demonstrada através de dados coletados em campo, uma concordância com o modelo teórico de circulação proposto por Ekman (1905).

Os padrões de circulação por correntes bem como o modelo de circulação para águas rasas, sob o domínio dos ventos incidentes, representam a primeira contribuição deste projeto de pesquisa. Pretende-se dar continuidade a aquisição de novas séries de dados, incluindo os parâmetros de ondas e a concentração de sedimentos em suspensão com a finalidade de aprimorar a interpretação dos mecanismos e dos padrões de circulação em águas rasas no litoral norte do estado do RS, bem como em outros ciclos sazonais.

Agradecimentos - Agradecemos a Coordenação de Aperfeiçoamento de Pessoal de Nível Superior (CAPES) pela concessão do auxílio financeiro através do Edital Ciências do Mar para a realização das campanhas oceanográficas, bem como pela Bolsa de Doutorado ao primeiro autor, aos revisores, os quais contribuíram fortemente para a melhoria do artigo, à empresa de navegação Mundial Serviços Marítimos Ltda e aos mergulhadores José Marinho e José D. Alves, pelo apoio logístico. Finalmente, agradecemos ao Instituto Nacional de Meteorologia (INMET) pelo fornecimento dos dados de vento. Este trabalho é parte da Tese de Doutorado do primeiro autor junto ao Programa de Pós-graduação em Geociências da UFRGS. 


\section{Referências}

Almeida, L.E.S.B., Rosauro, N.M.L. \& Toldo Jr., E.E. 1997. Análise Preliminar das Marés na Barra do Rio Tramandaí, RS - Brasil. XII SIMPÓSIO BRASILEIRO DE RECURSOS HÍDRICOS, Anais..., Vitória, ES. v.1, p.560566.

Barros, V.R., Grimm, A.M. \& Doyle, M.E. 2002. Relationship between temperature and circulation in Southwestern South America and its influence from El Niño and La Niña events. Journal of the Meteorological Society of Japan, 80: 21-32.

Bowden, K.F. 1983. Physical oceanography of coastal waters. New York. Halsted Press, 302 p.

Calliari, L.J. \& Fachin, S. 1993. Laguna dos Patos. Influência nos depósitos lamíticos costeiros. Pesquisas, 20(1): 57-69.

Calliari, L.J., Winterwerp, J.C., Fernandes, E., Cuchiara, D., Vinzon, S.B., Sperle, M. \& Holland, K.T. 2009. Fine grain sediment transport and deposition in the $\mathrm{Pa}$ tos Lagoon-Cassino beach sedimentary system. Continental Shelf Research, 29(3): 515-529.

Costa, R. 2009. Estudo sobre a variabilidade sazonal e da estrutura vertical das correntes costeiras da plataforma interna, ao largo de Rio Grande - RS. Rio Grande. 97p. Dissertação de Mestrado, Programa de Pós-Graduação em Oceanografia Física, Química e Geológica, Instituto de Oceanografia, Universidade Federal do Rio Grande.

Costa, R. \& Möller, 0.0. 2011. Estudo da estrutura e da variabilidade das correntes na área da plataforma interna ao largo de Rio Grande (RS, Brasil), no sudoeste do Atlântico Sul, durante a primavera-verão de 2006-2007. Revista da Gestão Costeira Integra$d a, 11(3):$ 273-281.

Csanady, G.T. 1976. Mean circulation in shallow seas. Journal of Geophysical Research, 81(30), 5389-5399.

Ekman, V.W. 1905. On the influence of earth's rotation on ocean currents. Arkiv for Matematik, Astronomi och Fysik, 2(11): 52p.

Fachin, S. 1998. Caracterização do Perfil de Equilíbrio da Antepraia na Costa do Rio Grande do Sul. Porto Alegre. 105 p. Dissertação de Mestrado, Programa de Pós-graduação em Geociências, Instituto de Geociências, Universidade Federal do Rio Grande do Sul. Universidade Federal do Rio Grande do Sul.

Figueiredo Jr., A.G. 1980. Response of water column to strong wind forcing, southern Brazilian inner shelf: implications for sand ridge formation. Marine Geology, 35: 367-376.

Ma, T.T.M. 2013. Quantificação do transporte longitudinal a partir de dados de concentração de sedimentos em suspensão, Tramandaí-RS. Porto Alegre. 72p. Dissertação de Mestrado, Programa de Pós-graduação em Geociências, Instituto de Geociências, Universidade Federal do Rio Grande do Sul. Universidade Federal do Rio Grande do Sul.
Miranda, L.B., Castro, B.M. \& Kjerve, B. 2002. Princípios de Oceanografia Física de Estuários. São Paulo, Edusp, 413p.

Nakano, K. 2006. Projeto Orla: implementação em territórios com urbanização consolidada. Coordenação de Kazuo Nakano. São Paulo: Instituto Polis; Brasília: Ministério do Planejamento, Orçamento e Gestão, 80 p.

Parise, C.K., Calliari, L.J. \& Krusche, N. 2009. Storm Surges and Beach Erosion in Southern Brazil: Atmospheric Conditions and Shore Erosion. Brazilian Journal of Oceanography, 57(3): 175-188.

Pepper, D.A. \& Stone G.W. 2004. Hydrodynamic and sedimentary responses to two contrasting winter storms on the inner shelf of the northern Gulf of Mexico. Marine Geology, 210: 43-62.

Piola, A.R., Matano, R.P., Palma, E., Möller, 0.0. \& Campos, E.J. 2005. The influence of the Plata river discharge on the western South Atlantic Shelf. Geophysical Research Letters, 32: 10-29.

Siegle, E. \& Calliari, L.J. 2008. High-Energy Events and Short-Term Changes in Superficial Beach Sediments. Brazilian Journal of Oceanography, 56(2): 149-152.

Smith, R.I. 1981. A comparison of the structure and variability of the flow field in three coastal upwelling regions: Oregon, Northwest Africa and Peru. Coastal Upwelling, (1981): 107-118.

Stanley, D.J. \& Swift, D. J. P. 1976. Marine Sediment Transport and Environment. Wiley-Interscience, New York, $602 \mathrm{p}$.

Strauch, J.C., Cuchiara, D.C., Toldo Jr., E.E. \& Almeida, L.E.S.B. 2009. O Padrão das Ondas de Verão e Outono no Litoral Sul e Norte do Rio Grande do Sul. Revista Brasileira de Recursos Hídricos, 14(4): 29-37.

Thompson, R. 1983. Low-Pass Filters to Suppress Inertial and Tidal Frequencies. Journal of Physical Oceanography, 13: 1077-1083.

Toldo Jr., E.E., Dillenburg, S.R., Almeida, L.E.S.B., Tabajara, L.L., Martins, R. \& Cunha, L.O.B.P. 1993. Parâmetros morfométricos da Praia de Imbé, RS. Pesquisas, 20 (1): 27-32.

Toldo Jr, E.E., Nicolodi, J.L., Almeida, L.E.S.B., Corrêa, I.C.S. \& Esteves, L.S. 2006. Coastal dunes and shoreface width as a function of longshore transport. Journal of Coastal Research, 390-394.

Villwock, J.A. \& Tomazelli, L.J. 1995. Geologia Costeira do Rio Grande do Sul. Notas Técnicas do CECO-IG-UFRGS, Porto Alegre, 8:1-45.

Welch, P. 1967. The use of fast Fourier transform for the estimation of power spectra: A method based on time averaging over short, modified periodograms. IEEE Transactions on audio and electroacoustics, 15(2): 70-73.

Zavialov, P., Möller, 0.0.Jr. \& Campos, E. 2002. First direct measurements of currents on the continental shelf of Southern Brazil. Continental Shelf Research, 22: 1975-1986. 